\title{
Pengaruh Latihan Circuit Training Terhadap Daya Tahan Kardiovaskuler Pada Tim Futsal Universitas Pgri Semarang
}

\author{
Zihni Ashfahani $^{1 凶}$ \\ Program Studi Pendidikan Jasmani Kesehatan dan Rekreasi, Fakultas Pendidikan \\ IImu Pengetahuan Sosial dan Keolahragaan, Universitas PGRI Semarang \\ zihniashfahani20@gmail.com
}

\section{Article Info}

History Articles

Submitted : 17 Januari 2020

Reviewed : 18 Juni 2020

Accepted : 14 Juli 2020

\section{Keywords}

Kecepatan lari; Panjang

Tungkai; Power otot tungkai

\begin{abstract}
Abstrak
Penelitian ini bertujuan untuk mengetahui seberapa besar pengaruh latihan sirkuit dalam upaya meningkatkan daya tahan kardiovaskuler melalui peningkatan VO2max. Penelitian ini merupakan penelitian kuantitatif, pengambilan data menggunakan metode eskperimen dengan desain penelitian one group pre-test-post-test design .Instrumen yang digunakan untuk mengukur VO2max adalah Multistage Fitness Test (MFT). Subjek dalam penelitian ini adalah Tim Futsal Putra UPGRIS yang berjumlah 15 yang mana sampel diambil secara acak atau random sampling. Teknik analisis data yang digunakan adalah analisis deskriptif kuantitatif yang dikonversikan dalam bentuk persentase. Hasil penelitian diketahui tingkat daya tahan kardiovaskuler berdasarkan tingkat VO2max pada Tim Futsal Putra UPGRIS yang diukur menggunakan MFT (Multistage Fitness Test) adalah 26,67\% (4 pemain) berada pada kategori cukup, 40\% (6 pemain) berada pada kategori baik, 20\% berada pada kategori sangat baik dan $13,33 \%$ (2 pemain) berada pada kategori istimewa. Berdasarkan hasil penelitian maka dapat disimpulkan bahwa ada pengaruh latihan circuit training yang signifikan sebesar Sig. $(0,000)>$ $\alpha(0,05)$ dan selisih rata-rata pre-test dan post-test dengan persentase $7,22 \%$ terdahap daya tahan kardiovaskuler pada Tim Futsal Universitas PGRI Semarang. Penelitian ini diharapkan dapat dijadikan sebagai acuan dalam menyusun program latihan khususnya materi tentang peningkatan daya tahan kardiovaskuler pada pemain futsal
\end{abstract}

\section{Abstract}

This study aims to determine how much influence the circuit training has in efforts to improve cardiovascular endurance through increasing VO2max. This research is a quantitative study, data collection using an experimental method with one group pre-test-post-test design. The instrument used to measure VO2max is the Multistage Fitness Test (MFT). The subjects in this study were UPGRIS Putra Futsal Team, amounting to 15 in which samples were taken randomly or random sampling. The data analysis technique used is quantitative descriptive analysis which is converted as a percentage. The results of the study revealed that the level of cardiovascular endurance based on VO2max level in the UPGRIS Men's Futsal Team measured by MFT (Multistage Fitness Test) was $26.67 \%$ (4 players) in the sufficient category, $40 \%$ (6 players) were in the good category, $20 \%$ was in the excellent category and $13.33 \%$ (2 players) were in the special category. Based on the results of the study it can be concluded that there is a significant influence of circuit training exercises by Sig. $(0,000)>\alpha(0.05)$ and the difference between the average pretest and post-test with a percentage of $7.22 \%$ due to cardiovascular endurance in the Futsal Team of the University of PGRI Semarang. This research is expected to be used as a reference in compiling training programs specifically material on increasing cardiovascular endurance in futsal playersare far from perfection, and there are still things that need to be improved with further research better

(C) 2020 Semarang State University

Alamat korespondensi :

Alamat : Gedung Pusat Lt.3 Universitas PGRI Semarang

E-mail : zihniashfahani20@gmail.com 


\section{PENDAHULUAN}

Olahraga adalah serangkaian gerak raga yang teratur untuk mempertahankan kualitas hidup. Dengan berolahraga dapat meningkatkan derajat kesehatan, baik kesehatan jasmani maupun rohani. Hal ini sesuai dengan konsep sehat menurut Organisasi Kesehatan Dunia (WHO) bahwa: "sehat adalah sejahtera jasmani, rohani dan sosial, bukan hanya bebas dari penyakit, cacat ataupun kelemahan". Kegiatan olahraga dapat berupa latihan, pertandingan, rekreasi atau hiburan.

Olahragawan adalah pengolahraga yang mengikuti pelatihan secara teratur dan kejuaraan dengan penuh dedikasi untuk mencapai prestasi (Kementrian Pemuda dan Olahraga, 2012:2).

Menurut UU RI No.3 Tahun 2005 tentang sistem keolahragaan Nasional Bab 1 pasal 1 ayat 13 sebagai berikut :

"olahraga prestasi adalah olahraga yang membina dan mengembangkan olahragawan secara terencana, berjenjang dan berkelanjutan melalui kompetensi untuk mencapai prestasi tinggi dengan dukungan ilmu pengetahuan dan teknologi keolahragaan". Sesuai dengan pengertian olahraga prestasi tersebut di atas maka olahraga prestasi merupakan olahraga pembinaan dan pengembangan potensi dalam diri seseorang yang dilakukan secara terencana, berjenjang dan melalui kompetensi dengan tujuan untuk meraih prestasi tinggi.

Menurut Poerwodarminto dalam Mila Ratnawati yang dimaksud dengan prestasi adalah hasil yang telah dicapai, dilakukan atau dikerjakan oleh seseorang.

Sesuai UU No. 3 Tahun 2005 tentang Sistem Keolahragaan Nasional pada Bab 1 Ketentuan Umum poin ke-17 bahwa "prestasi merupakan hasil upaya maksimal yang dicapai olahragawan atau kelompok olahragawan (tim) dalam kegiatan olahraga".

Untuk meningkatkan prestasi dibutuhkan latihan yang efektif dan sangat optimal, oleh karena itu untuk menjalani suatu latihan agar optimal dibutuhkan suatu program latihan atlet.

Kondisi fisik atlet memegang peranan yang sangat penting dalam program latihan atlet. Program latihan kondisi fisik haruslah direncanakan secara baik dan sistematis dan ditujukan untuk meningkatkan kesegaran jasmani dan kemampuan fungsional dari sistem tubuh sehingga dengan demikian memungkinkan atlet untuk mencapai prestasi yang lebih baik. (Harsono, 2018:3).

Komponen fisik yang perlu diperhatikan untuk dikembangkan ada beberapa, diantaranya adalah daya tahan kardiovaskuler, daya tahan kekuatan, kekuatan otot (strength), kelentukan (flexibility), kecepatan (speed), stamina, kelincahan (agility), daya ledak otot (power), daya tahan kekuatan (strengthendurance). Komponen tersebut adalah yang utama harus dilatih dan dikembangkan oleh atlet cabang olahraga yang memerlukan komponenkomponen tersebut. (Harsono, 2018:40).

Kondisi fisik merupakan prasyarat yang harus dimiliki oleh seorang atlet dalam meningkatkan dan mengambangkan prestasi olahraga yang optimal, sehingga segenap kondisi fisiknya harus dikembangkan dan ditingkatkan sesuai dengan ciri, karakteristik dan kebutuhan masing-masing cabang olahraga (Eri Pratiknyo, 2010:1)

Dalam upaya untuk meningkatkan prestasi dalam cabang olahraga futsal, diperlukan beberapa komponen kondisi fisik yang dominan. Menurut Lhaksana (2011:17), "ada lima komponen yang dominan dalam latihan fisik untuk olahraga futsal yaitu daya tahan, kecepatan, kekuatan, koordinasi dan kelincahan". 
Melihat karakteristik cabang olahraga futsal, dapat disimpulkan bahwa komponen yang harus lebih dominan dimiliki pemain futsal adalah daya tahan. Daya tahan ada dua, yaitu daya tahan umum atau daya tahan kardiovaskuler atau general endurance, dan daya tahan otot atau muscle endurance.

Daya tahan umum merupakan kemampuan seseorang untuk melakukan kegiatan yang berintensitas sedang diseluruh tubuh dan sebagian besar otot untuk periode waktu yang lama. Daya tahan otot adalah kemampuan otot atau sekelompok otot untuk melakukan kontraksi yang berulang-ulang pada periode waktu yang lama (Eri Pratiknyo, 2010:2).

Untuk memenuhi salah satu komponen kondisi fisik tersebut yaitu tuntutan daya tahan para anggota Tim Futsal Universitas PGRI Semarang harus mempunyai energi dalam jumlah banyak. Tuntutan energi dalam jumlah banyak itu akan diproduksi melalui sistem aerobik yang memerlukan oksigen, oleh karena itu tinggi rendahnya daya tahan pemain futsal Universitas PGRI Semarang tergantung dari tinggi rendahnya kapasitas oksigen maksimal atau VO2max. Dengan begitu VO2max seorang atlet harus lebih baik daripada orang-orang umumnya agar tercipta kerja yang mumpuni dalam bidangnya (Ario Debbian, dkk 2016:20). Seseorang yang kebugarannya baik akan memiliki nilai VO2max yang lebih tinggi dan dapat melakukan aktivitas lebih kuat (Faramita Nur Izzaty, dkk 2015:764).

Untuk memiliki kemampuan daya tahan aerobik yang tinggi diperlukan tingkat VO2max yang tinggi pula. Tinggi rendahnya VO2max seseorang dipengaruhi oleh beberapa komponen penunjang seperti kemampuan jantung, paruparu, kualitas darah, pembuluh darah dan kemampuan otot rangka yang akan mengkonsumsi oksigen tersebut. Apabila salah satu dari komponen tersebut memiliki kemampuan rendah, maka akan berpengaruh terhadap tingkat VO2max (Abraham, 2012:2).

Dari data awal didapatkan hasil VO2max pemain tim futsal UPGRIS dengan kategori sangat kurang ada 1 (satu) orang dengan nilai < 33,0. Kategori kurang ada 8 (delapan) orang dengan nilai 33,0 - 36,4. Kategori cukup ada 6 (enam) orang dengan nilai 36,5 - 42,4. Kategori baik ada 3 (tiga) orang dengan nilai 42,5 - 46,4. Kategori sangat baik ada 1 (satu) orang dengan nilai 46,5 - 52,4. Dan kategori istimewa ada 1 (satu) orang dengan nilai > 52,4 Berikut penjelasan jika digambarkan dalam bentuk diagram:

Dari uraian di atas dapat dikatakan bahwa daya tahan kardiovaskuler Tim Futsal Putra UPGRIS masih lemah karena jumlah yang berkategori kurang lebih banyak. Maka dibutuhkan adanya suatu alternatif pelatihan yang bisa digunakan dan diterapkan dalam meningkatkan VO2max yaitu circuit training. Karena circuit training ini merupakan suatu sistem latihan yang dapat memperbaiki secara serempak fitness keseluruhan dari tubuh yaitu unsur-unsur power, daya tahan, kekuatan, kelincahan, kecepatan dan komponen kondisi fisik lainnya (Yudiana, 2010:2). Hal ini bertujuan agar Tim Futsal UPGRIS mengalami peningkatan daya tahan kardiovaskuler terutama pada konsumsi VO2max sehingga kualitas bermain di dalam pertandingan di event berikutnya dapat meningkat sehingga prestasi pun diharapkan akan meningkat.

Oleh karena itu penulis melakukan suatu penelitian yang berjudul Pengaruh Latihan Circuit Training terhadap Daya Tahan Kardiovaskuler pada Tim Futsal Universitas PGRI Semarang.

Tujuan penelitian ini Untuk mengetahui pengaruh latihan circuit training terhadap daya 
tahan kardiovaskuler pada tim futsal Universitas PGRI Semarang

\section{METODE}

Metode yang digunakan dalam penelitian ini adalah metode eksperimen yang mana merupakan penelitian Pre-Experimental Design (Nondesign) atau eksperimen semu. Sugiyono (2015:107) menjelaskan bahwa, "metode penelitian eksperimen dapat diartikan sebagai metode penelitian yang digunakan untuk mencari pengaruh perlakuan tertentu terhadap yang lain dalam kondisi yang terkendalikan".

Desain yang digunakan dalam peneltian ini adalah dengan rancangan one-group pretestposttest design.

Populasi dalam penelitian ini adalah tim futsal putra Universitas PGRI Semarang yang masih aktif mengikuti propgram latihan rutin dengan jumlah 20. Pengambilan popualasi hanya pada mahasiswa putra saja ini dimaksudkan agar dalam pengolahan data lebih seragam (homogen). Teknik pengambilan sampel yang digunakan adalah Purpose Sampling dengan jumlahg sampel 15.

Instrumen yang digunakan dalam penelitian ini adalah Instrumen Multistage Fitness Test (MFT) yang mana digunakan ketika observasi, pre-test, dan post-test.

\section{HASIL DAN PEMBAHASAN}

Penelitian ini membahas tentang upaya untuk meningkatkan salah satu komponen kondisi fisik yaitu daya tahan kardiovaskuler yang menggunakan model latihan circuit training dengan metode eksperimen. Dimana komponen penilaian daya tahan kardiovaskuler dilakukan melalui MFT (Multistage Fitness Tes).

Hasil uji hipotesis statistik yang dilakukan menggunakan Paired Sample T-Test dengan syarat uji normalitas dan homogenitas terpenuhi.
Melalui uji paired sample T-test diperoleh nilai Thitung sebesar $-14,008$ dengan T-tabel $(\alpha=0,05$, $d f=14)$ sebesar 2,145 serta Sig, $(0,000)<a$ $(0,05)$. Oleh karena itu Ho ditolak yang artinya ada perbedaan hasil pre-test dan post-test sehingga dapat dikatakan bahwa ada peningkatan aspek daya tahan para pemain futsal putra di UKM Futsal UPGRIS karena pengaruh latihan sirkuit.

Berdasarkan hasil analisis rata-rata pretest dan post-test daya tahan (MFT) diperoleh hasil persentase statistik data akhir yaitu 26,67\% berjumlah 4 orang pada kategori cukup, $40 \%$ berjumlah 6 orang pada kategori baik, $20 \%$ berjumlah 3 orang pada kategori sangat baik, dan $13,33 \%$ berjumlah 2 orang pada kategori istimewa.

Dalam penelitian ini diperoleh hasil selisih rata-rata pre-test dan post-test dengan persentase $7,22 \%$ dengan kategori baik

\section{KESIMPULAN}

Berdasarkan hasil penelitian dapat disimpulkan bahwa circuit training dapat meningkatkan kualitas permainan dan performa fisik para pemain futsal putra UPGRIS terutama pada komponen daya tahan kardiovaskuler. Maka dapat dikatakan ada pengaruh latihan circuit training yang signifikan sebesar Sig. $(0,000)<\alpha(0,05)$ dan selisih rata-rata pre-test dan post-test dengan persentase $7,22 \%$ terdahap daya tahan kardiovaskuler pada Tim Futsal Universitas PGRI Semarang.

Rekomendasi dari penelitian ini yaitu sebagiai berikut:

\section{a. Bagi Pelatih}

Hasil penelitian ini dapat dijadikan sebagai salah satu tolak ukur atau acuan dalam menyusun program latihan khususnya materi 
tentang peningkatan kondisi daya tahan kardiovaskuler pada pemain futsal.

b. Bagi Pemain Futsal

Hasil penelitian ini dapat dijadikan motivasi dalam mengejar cita-cita sebagai pemain futsal profesional karena dengan berlatih secara tekun, semangat dan dengan program latihan yang baik pula, latihan dapat meningkatkan kondisi fisik dan daya tahan

c. Bagi Peneliti Lain

Perlu diadakan penelitian yang sejenis dengan:

1) Menambah variabel penelitian yang terkait dengan kecepatan.

2) Subjek penelitian tidak hanya terbatas pada satu kelompok.

3) Melakukan pengontrolan gizi, kesehatan, dan aktivitas fisik di luar jam latihan sirkuit

\section{DAFTAR PUSTAKA}

Abraham, H. 2012 Analisis Tingkat Vo2max pada atlet sepakbola di pplp sulawesi Selatan. 2(4)

Harsono. (2018). Latihan Kondisi Fisik.Bandung: PT. Remaja

Rosdakarya.Izzaty, Faramita Nur (2015). Perbandingan nilai VO2max pada pesenam Aqua Zumba dengan pesenam zumba. Kementrian Pemuda dan Olahraga (2012). Prestasi Olahraga.

Lhaksana, J. (2011). Taktik dan StrategiFUTSAL Modern. Depok: Be Champion.

Razak, Abraham (2012). Analisis Tingkat Vo2max Pada Atlet Sepakbola Di Pplp Sulawesi Selatan.

Sugiyono (2015). Metode Penelitian Pendidikan Pendekatan Kuantitatif, Kualitatif, dan R\&D. Bandung: Alfabeta.

Sukadiyanto (2011). Pengantar Teori dan Metodologi Melatih Fisik. Bandung: CV. Lubuk Agung.

Sukmadinata, Nana Syaodih (2013). Metode Penelitian Pendidikan. Bandung: PT Remaja Rosdakarya.

Undang-Undang RI No.3 Tahun 2005 Tentang Sistem Keolahragaan Nasional.

Utomo, Bagus Dwi Wahyu (2014). Pengaruh Latihan Circuit Training terhadap
Peningkatan Volume Oksigen Maksimal (VO2 Maks) pada Atlet di PB Speed Tembokrejo Muncar Banyuwangi.

Wiarto, Giri (2013). Fisiologi Olahraga. Yogyakarta: Graha IImu.

Wiarto, Giri (2015). Panduan Berolahraga untuk Kesehatan dan Kebugaran.

Yogyakarta: Graha Ilmu. Widigda, Farid (2018). Pengaruh Latihan

Circuit Training terhadap Peningkatan Kecepatan Lari Tim Softball UPGRIS. Skripsi. Universitas PGRISemarang.

Yudiana, Y., Subardjah, H., \& Juliantine, T. 2010. Latihan Fisik. Bandung: FPOK- UPI. Tersedia di http://eprints. uny. ac. id/ [Diakses 10 April 2019.].

Zona Pelatih (2016). Program Latihan Menggunakan Circuit Training. http://www.zonapelatih.net/2016/02/program -latihan-menggunakan-circuit.html. (diakses pada tanggal 28 Juli 2019). 